\title{
JOURNAL.RU
}

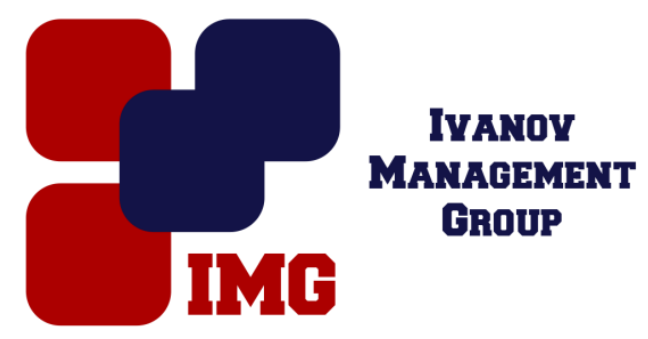

Голядинец О.А., Гаврилов С.И. Наииональный исследовательский ядерный университет «МИФИ» Москва, Россия

doi: 10.18411/1j-30-06-2017-19

idsp 000001:1j-30-06-2017-19

\section{Разработка системы учета затрат в TMS-системах}

\section{Аннотация}

Перевозка грузов является динамично развивающейся областью деятельности в современном мире. Однако, необходимо иметь возможность определить рентабельность данной деятельности, то есть определить приносят ли перевозки прибыль. Данная статья посвящена разработке системы учета затрат в TMS-системах.

Ключевые слова: TMS-системы, управление перевозами, учет затрат, рентабельность.

В современном мире происходит постоянное развитие интернет технологий, в том числе и интернет-магазинов. Данный сегмент рынка постоянно развивается, так, по данным исследования компании shopconstructor, обороты крупных компаний интернет-торговли достигли 37000 млн. рублей в год, а количество заказов - 7360000. [1] Соответственно, возникает острая необходимость доставки товаров до покупателя. Для управления перевозками и автотранспортом в работе предприятия применяются TMS-системы, образующие целый класс информационных систем. Однако, кроме непосредственного управления процессом перевозки, актуальной проблемой также является возможность определения рентабельности перевозки. В ходе выполнения доставки могут возникнуть ситуации, когда выгода от продажи товара оказывается меньше, чем расходы на доставку товара до получателя. Некоторые транспортные системы, например, AXELOTTMS 3, позволяют вести учет затрат, но нигде нет описания структуры учета затрат в транспортной 
системе [2]. В данной статье предложен способ распределения затрат по транспортной логистике, позволяющий определить рентабельность перевозок.

Процесс перевозок связан с постоянными расходами на транспортировку. Перевозки могут осуществляться как собственными транспортными средствами, так наемными. Если перевозка осуществляется наемными транспортными средствами, то транспортные расходы связаны в основном только с оплатой услуг сторонних перевозчиков. Если же перевозка выполняется собственными ТC с привлечением сотрудников организации, то в данном случае распределение расходов значительно сложнее. Для начала необходимо понять сам принцип распределения затрат в TMS-системе.

Для получения возможности ведения адекватного учета доходности перевозок организации необходимо распределять как доходы от перевозки, так и расходы на обеспечение перевозки. В случае с доходами дело обстоит проще, поскольку они могут фиксироваться по каждой перевозке, то есть каждый заказ от клиента соответствует документу Заявка на перевозку грузов в системе TMS, по которому могут быть зафиксированы фактические доходы. То есть все доходы по каждому заказу могут быть зафиксированы в системе TMS. Теперь необходимо понять, как учитывать расходы. Так как Заявки на перевозку грузов в транспортных системах распределяются в рейсы, то и расходы необходимо распределять на рейсы. Это позволит разнести расходы на Заявки, чтобы на основании доходов и расходов определить рентабельность каждой конкретной перевозки. Отдельно стоит отметить принципы распределения расходов из рейса по заявкам: если просто распределить в равных долях, то будет некорректная информация, поскольку затраты на перевозку грузов по каждому заказу различны. В целом существует достаточно большое количество возможных вариантов распределения, которые позволяют задать TMS-системы, но основным распределением является тонна-километр, то есть сколько массы груза и на какое расстояние было перевезено[3]. То есть, все расходы, которые будут распределены из рейсов на соответствующие им заявки отнесутся на основании выбранного распределения, что позволит корректно оценить расходы, которые понесла компания на перевозку грузов по конкретному заказу.

Далее необходимо определить какие расходы вообще могут быть распределены на рейсы. Затраты можно разделить на две группы: прямые затраты и косвенные. Прямыми могут выступать затраты, которые можно однозначно распределить на конкретный рейс. Например, зарплата водителю по рейсу или затраты горюче-смазочных материалов (ГСМ) на рейс согласно 
Путевому листу. К косвенным расходам относятся те, которые не могут быть распределены на рейс напрямую[4]. К косвенным расходам можно отнести следующие расходы:

- Амортизация ТС - расход может распределять по сроку полезного использования или по пробегу.

- Приобретение агрегатов и материалов - данные расходы распределяются аналогично амортизации - на срок полезного использования или по пробегу.

- Ремонты - ремонты также не связываются с конкретными рейсами, а потому относятся к косвенным расходам.

- Расход ГСМ - сюда может относиться расход на технические рейсы, во время которых ТС ездит до места ремонта.

- Штрафы и дорожные происшествия - часто сложно определить к какому рейсу присваивается конкретное нарушение или ДТП, поэтому подобные случаи следует относить к косвенным расходам.

- Прочие расходы.

Если взглянуть на косвенные расходы, то видно, что они относятся к конкретному транспортному средству. Соответственно все расходы по транспортным средствам могут относиться на рейсы, которые они выполняли пропорционально выбранному распределению. Таким образом, полученная схема распределения затрат в транспортных системах, которая позволяет определить рентабельность перевозки представлена на рисунке 1.

В данной работе представлена система учета затрат в TMS-системах, которая позволяет распределять расходы и доходы на перевозки на конкретные заказы клиентов, что позволяет определить рентабельность не только в целом, но и в разрезе каждого заказа. Такое распределение позволяет эффективно управлять процессом перевозок и вести корректный учет затрат в TMS-системе. 


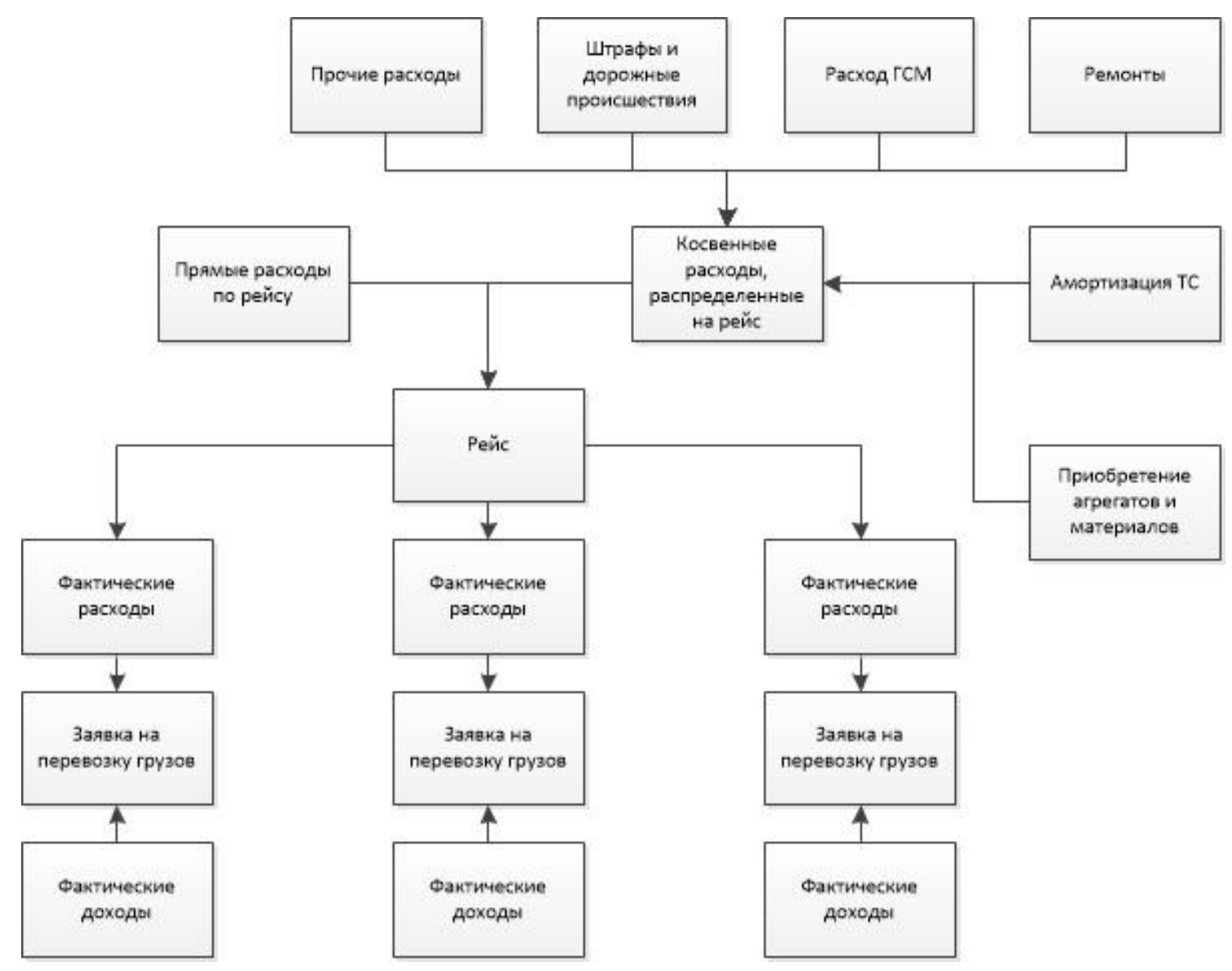

Pис. 1. Схема учета затрат в TMS-системе.

\section{Литература}

1. Интернет-продажи в России: статистика, аналитика, конверсия, прогноз // Агентство Shopconstructor - Режим доступа: https://shopconstructor.ru/internet-prodazhi-v-rossiistatistika-analitika-konversiya.

2. AXELOT [Электронный pecypc]: - Режим доступа: https://logistics.axelot.ru/service/avtomatizacija_transportnoi_logistiki/, свободный. - Загл. с экрана. (дата обращения: 17.05.2017);

3. А.В. Вельможин, В.А. Гудков, Л.Б. Миротин, Грузовые автомобильные перевозки: учебник для вузов // М.: Горячая линия - Телеком - 2007. - 560 с.;

4. Витвицкий Е.Е. Теория транспортных процессов и систем (Грузовые автомобильные перевозки): учебное пособие // Омск: Изд-во СибАДИ,2010. - 207 с.; 